\title{
The association of two single-nucleotide polymorphisms of the FOXP3 gene (rs3761548 and rs3761547) with renal allograft function and survival in kidney transplant recipients
}

\author{
Vahideh Ebrahimzadeh Attari ${ }^{\circledR}$, Seyed Sadroddin Rasi Hashemi ${ }^{\circledR}{ }^{\circledR}$, Solmaz Oloufi², Leili Aghebati Maleki ${ }^{\circledR}{ }^{\circledR}$, Dariush

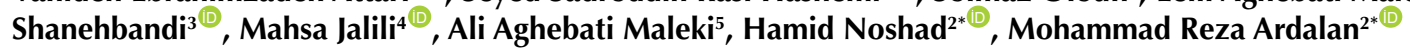 \\ ${ }^{1}$ Department of Nutrition and Food Sciences, Maragheh University of Medical Sciences, Maragheh, Iran \\ ${ }^{2}$ Kidney Research Center, Tabriz University of Medical Sciences, Tabriz, Iran \\ ${ }^{3}$ Immunology Research Center, Tabriz University of Medical Sciences, Tabriz, Iran \\ ${ }^{4}$ Department of Biology, Norwegian University of Science and Technology (NTNU), Trondheim, Norway \\ ${ }^{5}$ Zanjan University of Medical Sciences, Zanjan, Iran
}

\section{*Correspondence to Prof. Mohammad Reza Ardalan, Email: ardalan34@ yahoo.com, ardalanm@ tbzmed.ac.ir, Hamid Noshad, Email: hamidnoshad1@yahoo. com}

Received 13 June 2020 Accepted 3 Oct. 2020 Published online 2 Nov. 2020

Keywords: FOXP3, Polymorphism, Genotype, Kidney function, Kidney transplant

\begin{abstract}
Introduction: The FOXP3 protein is an immune regulatory protein that specifically maintains the function and differentiation of regulatory $\mathrm{T}$ cells (Tregs) and prevents autoimmunity. Variations in FOXP3 gene may alter its function and also the immune response.

Objectives: The present study was conducted to investigate the association of the FOXP3 gene polymorphisms -3499 A/G and -3279 A/C with renal allograft function and survival in kidney transplant recipients.

Patients and Methods: In this cross-sectional study, 150 eligible kidney transplant recipients were evaluated. Kidney function was evaluated at three- and five-year post-transplant using serum creatinine level and glomerular filtration rate as indicators. Genotyping of the study participants was performed using the PCRrestriction fragment length polymorphism method.

Results: The frequencies of AA, AG, and GG genotypes of the -3499 A/G polymorphism were $62.42 \%, 29.53 \%$, and $8.05 \%$, respectively. For the $-3279 \mathrm{~A} / \mathrm{C}$ polymorphism, the frequencies of the $\mathrm{AA}, \mathrm{AC}$, and CC genotypes were $21.33 \%, 32 \%$, and $46.67 \%$, respectively. The mean \pm SD of serum creatinine level, three and five years after transplantation were $1.70 \pm 1.58$ and $1.87 \pm 1.94$, respectively. Serum creatinine level and kidney function did not show any significant association with these polymorphisms.

Conclusion: In the present study, only $10 \%$ of participants experienced episodes of severe kidney dysfunction and we did not find any significant association between kidney function and the subjects' genotypes. Further epidemiologic studies with greater sample sizes may be needed to clarify this association.
\end{abstract}

\section{Introduction}

Kidney transplantation has recently been accompanied by increased quality of life and decreased clinical complications. However, acute rejection continues to occur in $20-40 \%$ of kidney transplant recipients. In addition, chronic rejection is the major cause of renal failure in long-term transplants. Thus, identification of the markers associated with acute and chronic kidney transplant failure will be beneficial (1).

Regulatory $\mathrm{T}$ cells play an important role in regulation of the immune response to antigens, allergens, infections, and tumors. The FOXP3 protein, also known as scurfin, is a transcription factor and an immune regulatory protein that specifically maintain

\section{Key point}

In a study on 150 eligible kidney transplant recipients, only $10 \%$ of participants experienced episodes of severe kidney dysfunction and we did not find any significant association between kidney function and FOXP3 gene polymorphisms.

the function and differentiation of regulatory $\mathrm{T}$ cells (Tregs) and prevent autoimmunity $(2,3)$.

The FOXP3 gene is located on the $\mathrm{X}$ chromosome (p11.23-q13.3) and consists of 11 exons $(1,4)$. Some of the genetic variations of this gene may alter its function and expression and thus affect the immune response. These genetic variations may also

Copyright $\odot 2021$ The Author(s); Published by Nickan Research Institute. This is an open-access article distributed under the terms of the Creative Commons Attribution License (http://creativecommons.org/licenses/by/4.0), which permits unrestricted use, distribution, and reproduction in any medium, provided the original work is properly cited. 
lead to increased predisposition to certain autoimmune disorders $(5,6)$. It has been reported that low transcription rate of the FOXP3 gene as a result of genetic changes and mutations could lead to severe and fatal pro-inflammatory immune responses $(2,3,7,8)$. There is also evidence that genetic variants of FOXP3 influence graft survival in kidney transplant patients $(9,10)$.

Two mutations (-3499 A/G [rs3761547] and -3279 $\mathrm{A} / \mathrm{C}$ [rs3761548]) in the promoter region of FOXP3 gene are very common and may affect its genetic expression $(11,12)$. Recent research has demonstrated an increased risk of transplant rejection and decreased renal function in individuals carrying the -3279 AA genotype versus -3279 CC (1). FOXP3 gene polymorphisms have also been associated with circulating levels of tacrolimus (13, 14). The FOXP3 rs3761548 polymorphism has also been shown to be associated with acute complications after kidney transplant (14).

\section{Objectives}

There is little evidence regarding the association between these FOXP3 polymorphisms and allograft survival. Therefore, the present study was conducted to investigate the association of the FOXP3 gene polymorphisms -3499 $\mathrm{A} / \mathrm{G}$ and -3279 A/C with renal allograft function and survival in kidney transplant recipients.

\section{Patients and Methods}

\section{Study design and subjects}

The present cross-sectional study investigated kidney transplant recipients who were referred to Imam Reza hospital (Tabriz, Iran). The exclusion criteria were as follows; patients who were younger than 15 years of age, patients who had urological and kidney stone problems, patients who were affected by HIV, cytomegalovirus or hepatitis B virus; and patients who had a history of previous transplantation. Accordingly, a total of 150 patients were enrolled voluntarily in the study.

\section{Data collection}

Different data including patients' age, gender, type of dialysis, medications, any evidence of allograft rejection and mortality rate were recorded in a questionnaire. Kidney function three- and five-years post-transplantation was assessed using the registered serum creatinine levels and then glomerular filtration rate (GFR) was calculated.

GFR was estimated based on the CKD-EPI (Chronic Kidney Disease Epidemiology Collaboration) equation (2009) using the online eGFR calculator of the National Kidney Foundation (https://www.kidney.org/professionals/ KDOQI/gfr_calculator). Genomic DNA was extracted from whole blood using the phenol-chloroform DNA extraction method.

\section{Designing specific primers and PCR amplification} Specific primers were used for amplification of the region containing rs3761547 A/G and rs3761548 A/C singlenucleotide polymorphisms (SNPs). BDF47 (5'- CAA TCC TCC TCT CGC ACA CA-3') and BDF48 (5'- CCT CTC CGT GCT CAG TGT AG -3') were used as forward primers, and BDR47 (5'- CAC AGC CTG ACT GAC TGA CAT - $3^{\prime}$ ) and BDF48 (5'-CAC AGC CTG ACT GAC TGA CAT- $3^{\prime}$ ) were used as reverse primers. Polymerase chain reaction (PCR) amplification was carried out in a final volume of $25 \mu \mathrm{L}$ using a Peqlab thermal cycler. Each reaction contained $20 \mathrm{ng}$ of DNA, $0.5 \mu \mathrm{M}$ of each primer, and $12.5 \mu \mathrm{L}$ of Amplicon TM 2x master mix (Amplicon, Herlev, Denmark). PCR conditions included an initial denaturation step at $95^{\circ} \mathrm{C}$ for 4 minutes, which was followed by 35 cycles of denaturation at $94^{\circ} \mathrm{C}$ for 50 seconds, annealing at $59^{\circ} \mathrm{C}$ for 50 seconds, and extension at $72^{\circ} \mathrm{C}$ for 80 seconds, and a final extension step of $72^{\circ} \mathrm{C}$ for 5 minutes. PCR products were detected by $2 \%(\mathrm{w} / \mathrm{v})$ agarose gel electrophoresis in TAE buffer stained with SYBR Green (DNA safe stain, Tehran, Iran).

\section{Genotyping of the SNPs in the FOXP3 gene}

For genotyping the rs3761547 (-3499A/G) and rs3761548 (-3279 A/C) polymorphisms, PCR-restriction fragment length polymorphism was performed, and PCR products were digested by MunI and Pst I enzymes, respectively. Each reaction contained $7 \mu \mathrm{L}$ of purified PCR product, $2 \mu \mathrm{L}$ of $10 \times$ enzyme buffer, 5 units of restriction enzyme, and nuclease free water up to a final volume of $20 \mu \mathrm{L}$. The reactions were incubated overnight at $37^{\circ} \mathrm{C}$ and digested products were visualized by ultraviolet trans-illumination after electrophoresis on $2 \%$ agarose gels stained with SYBR Green (DNA safe stains, Tehran, Iran).

\section{Ethical issues}

Human rights were respected in accordance with the Declaration of Helsinki (1975), as revised in 1983. The ethics committee of Tabriz University of Medical Sciences approved this study (ethical code \#IR.TBZMED. REC.1396.176). Written informed consent was obtained from the patients. This study was extracted from the MD thesis of Solmaz Oloufi at Tabriz University of Medical Sciences, following the standard protocols of the university research ethics committee.

\section{Statistical analysis}

Data were analyzed using SPSS software, version 21.0 (IBM Corp., Armonk, NY, USA). The normal distribution of variables was tested by the Kolmogorov-Smirnov test. Results were reported as mean (SD), if not otherwise stated. Wilcoxon signed-rank test was used to assess time effect on creatinine level and GFR, regarding their nonparametric feature. The differences of the genotype and allele frequencies of both SNPs were calculated. All genotype distributions were tested for deviation from the Hardy-Weinberg equation using the PopGene.S2 software based on the chi-square test $(P>0.05)$. The association 
between serum creatinine levels and kidney function with genotypes was assessed using Spearman's rho correlation test. The significance level was set at $P=0.05$.

\section{Results}

A total of 150 native Iranian-Azari eligible patients (88 men and 62 women; mean age $38.97 \pm 12.75$ years) participated in the present study. Additional general data are presented in Table 1.

\section{Patients' kidney function}

Data regarding the kidney function of all patients are presented in Table 2. Due to the abnormality of the data distribution, the $25^{\text {th }}$ and 75 th percentiles (IQR) were reported in addition to the mean and standard deviation. It should be noted that the comparison of the above indices of kidney function did not show a significant difference between the two genders $(P>0.05)$. In addition, a survey at five-year post-transplantation was performed in only $23 \%$ of subjects $(\mathrm{n}=35)$. According to the Wilcoxon signed-rank test, no significant change in the creatinine level and GFR was observed three and five years after transplantation in 35 subjects.

FOXP3 rs3761547 (-3499 A/G) polymorphism (FOXP3-1) The genotypic frequencies of the participants with regard

Table 1. General characteristics of the subjects

\begin{tabular}{lc}
\hline Variable & No. $(\%)$ or Mean \pm SD \\
\hline Age $(y)$ & $38.97 \pm 12.75$ \\
\hline Total & $37.93 \pm 13.16$ \\
Male & $40.44 \pm 12.43$ \\
Female & \\
Gender & $88(58.7)$ \\
Man & $62(41.3)$ \\
Female & $67(44.7)$ \\
Immunosuppressive drug & $83(55.3)$ \\
\hline Tacrolimus & $134(89.3)$ \\
Cyclosporine & $16(10.6)$ \\
\hline Type of graft & \\
\hline Live giver & \\
Brain death & \\
\hline
\end{tabular}

Table 2. Results related to patients' kidney function three and five years after transplantation

\begin{tabular}{|c|c|c|c|}
\hline Parameter & Mean \pm SD & $\begin{array}{c}\text { IQR (75th percentile- } \\
\text { 25th percentile) }\end{array}$ & $\boldsymbol{P}^{*}$ \\
\hline Creatinine 3 (mg/dL) & $1.70 \pm 1.58$ & $1.20(1.10-1.65)$ & $>0.05$ \\
\hline Creatinine 5 (mg/dL) & $1.87 \pm 1.94$ & $1.87(1.00-1.60)$ & \\
\hline $\begin{array}{l}\text { eGFR -EPI } 3(\mathrm{~mL} / \\
\left.\mathrm{min} / 1.73 \mathrm{~m}^{2}\right)\end{array}$ & $73.90 \pm 22.54$ & $73.90(57.75-89.25)$ & $>0.05$ \\
\hline $\begin{array}{l}\text { eGFR -EPI } 5(\mathrm{~mL} / \\
\left.\mathrm{min} / 1.73 \mathrm{~m}^{2}\right)\end{array}$ & $73.52 \pm 22.44$ & $73.90(57.50-88.75)$ & \\
\hline
\end{tabular}

*Based on Wilcoxon signed-rank test. to the FOXP3 -3499A/G polymorphism are presented in Table 3 according to number, percentage, and study groups, respectively.

The frequencies of the GG, GA, and AA genotypes for the FOXP3-1 polymorphism in the female subgroup were $9.09 \%, 36.36 \%$, and $54.54 \%$, respectively; in the male subgroup, the frequencies were $8.06 \%, 35 \%$, and $58 \%$, respectively. Comparison of the genotype frequencies between the two groups using chi-square test revealed no significant difference $(P=0.120)$.

The frequencies of allele $\mathrm{A}$ in the total population and male and female groups were 0.771, 0.822, and 0.727, respectively. Statistical analysis showed that HardyWeinberg equilibrium was in the total group and the population was in equilibrium $(P>0.05)$. However, in the male subgroup, this balance was not observed $(P=0.03)$.

FOXP3 rs3761548 (-3279A/C) polymorphism (FOXP3-2) The genotypic frequencies of the participants with regard to the FOXP3 -3279 A/C polymorphism are presented in Table 4 according to number, percentage, and study groups, respectively.

The frequencies of the $\mathrm{CC}, \mathrm{AC}$, and AA genotypes for the FOXP3-2 polymorphism in the female subgroup were $47.72 \%, 30.68 \%$, and $21.59 \%$, respectively; in the male subgroup, the frequencies were $45.16 \%, 33.87 \%$, and $97 \%$, respectively. Comparison of the frequency of the genotypes between the two subgroups using the chisquare test showed no significant difference $(P=0.831)$. Furthermore, the frequency of allele $\mathrm{A}$ in total population and male and female subgroups was 0.369, 0.379, and 0.373 , respectively. Statistical analysis showed that HardyWeinberg equilibrium was not in place at all, and the population was not in equilibrium $(P<0.05)$. However, the male subgroup showed a Hardy-Weinberg equilibrium $(P=0.09)$.

Association of renal function with the studied polymorphisms

The association of renal function with the studied polymorphisms of the FOXP3 gene is presented in Table 5. Based on the findings of the present study, serum creatinine level and GFR at three and five years after kidney transplantation were not correlated with the studied polymorphisms $(P>0.05)$. Based on the low values of the Spearman's rho correlation coefficient (beta; $0-0.2$ ), the association of renal function with the studied polymorphisms of the FOXP3 gene was clinically weak and non-significant.

In patients with renal transplantation, creatinine levels below $1.5 \mathrm{mg} / \mathrm{dL}$ are typically considered acceptable renal function, creatinine levels of 1.5 to $2.5 \mathrm{mg} / \mathrm{dL}$ are considered moderate renal dysfunction, and more than $2.5 \mathrm{mg} / \mathrm{dL}$ are considered severe renal dysfunction. Thus, in the present study, individuals were classified into three categories based on creatinine levels at the above-mentioned cut offs, and 
Table 3. Frequency of genotypes related to Foxp3-1 polymorphism (-3279A/C)

\begin{tabular}{|c|c|c|c|c|c|c|c|}
\hline \multirow{2}{*}{ Studied groups } & \multicolumn{3}{|c|}{ Foxp3-1 polymorphism } & \multirow{2}{*}{$\boldsymbol{P}^{*}$} & \multicolumn{2}{|c|}{ Allele frequency } & \multirow{2}{*}{$\boldsymbol{P}^{* *}$} \\
\hline & AA & AG & GG & & A & G & \\
\hline Woman $(\mathrm{n}=88)$ & $48(54.45 \%)$ & $32(36.36 \%)$ & $8(9.09 \%)$ & \multirow{2}{*}{0.12} & 0.773 & 0.272 & 0.740 \\
\hline $\operatorname{Man}(n=62)$ & $45(72.58 \%)$ & $12(19.35 \%)$ & $5(8.06 \%)$ & & 0.822 & 0.177 & 0.030 \\
\hline Total $(n=150)$ & $93(62.42 \%)$ & $44(29.53 \%)$ & $13(8.05 \%)$ & - & 0.771 & 0.228 & 0.090 \\
\hline
\end{tabular}

* Based on Chi square test.

** Based on Hardy Weinberg equation.

Table 4. Frequency of genotypes related to Foxp3-2 polymorphism (-3279A/C)

\begin{tabular}{|c|c|c|c|c|c|c|c|}
\hline \multirow{2}{*}{ Studied groups } & \multicolumn{3}{|c|}{ Foxp3-2 polymorphism } & \multirow{2}{*}{$\boldsymbol{P}^{*}$} & \multicolumn{2}{|c|}{ Allele frequency } & \multirow{2}{*}{$\boldsymbol{P}^{* *}$} \\
\hline & AA & $\mathrm{AC}$ & $\mathrm{CC}$ & & A & $\mathrm{C}$ & \\
\hline Woman $(n=88)$ & $19(21.59 \%)$ & $27(30.68 \%)$ & $42(47.72 \%)$ & \multirow{2}{*}{0.831} & 0.369 & 0.630 & 0.006 \\
\hline $\operatorname{Man}(n=62)$ & $13(20.97 \%)$ & $21(33.87 \%)$ & $28(45.16 \%)$ & & 0.379 & 0.621 & 0.090 \\
\hline Total $(n=150)$ & $31(21.33 \%)$ & $48(32.00 \%)$ & $70(46.67 \%)$ & - & 0.373 & 0.627 & 0.006 \\
\hline
\end{tabular}

* Based on Chi square test.

** Based on Hardy Weinberg equation.

their association with study FOXP3 gene polymorphisms was investigated. The results are reported in Tables 6 and 7. A total of 15 of 143 genotyped individuals had severe renal dysfunction, 25 had moderate dysfunction and 103 had acceptable function. After classification of creatinine

Table 5. Association of Kidney allograft function with FOXP3 Gene Polymorphisms

\begin{tabular}{lcccc}
\hline \multirow{2}{*}{ Parameter } & \multicolumn{2}{c}{ FOXP3-1 } & \multicolumn{2}{c}{ FOXP3-2 } \\
\cline { 2 - 5 } & $\boldsymbol{P}$ value* & Beta & P value* & Beta \\
\hline Creatinine 3 & 0.285 & 0.090 & 0.652 & -0.038 \\
Creatinine 5 & 0.770 & 0.052 & 0.539 & 0.109 \\
GFR 3 & 0.931 & -0.080 & 0.583 & 0.048 \\
GFR 5 & 0.760 & 0.056 & 0.554 & 0.109 \\
\hline
\end{tabular}

*Based on Spearman's rank-order correlation test.

Table 6. The Relationship between allograft function based on creatinine rating and genotype based on FOXP3-1

\begin{tabular}{lllll}
\hline \multirow{2}{*}{ Allograft function } & \multicolumn{3}{l}{ FOXP3-1 Genotypes } & \\
\cline { 2 - 4 } & AA & AG & GG & \\
\hline Acceptable & 66 & 31 & 6 & \\
The moderate disorder & 16 & 7 & 2 & 0.877 \\
The severe disorder & 9 & 4 & 2 & \\
\hline
\end{tabular}

* Based on chi-square test.

Table 7. The Relationship between allograft function based on creatinine rating and genotype based on FOXP3-2

\begin{tabular}{lllll}
\hline \multirow{2}{*}{ Allograft function } & \multicolumn{3}{l}{ FOXP3-2 Genotypes } & \\
\cline { 2 - 4 } & AA & AC & CC & \\
\hline Acceptable & 23 & 28 & 52 & \\
The moderate disorder & 4 & 8 & 13 & 0.422 \\
The severe disorder & 4 & 7 & 4 & \\
\hline
\end{tabular}

* Based on chi-square test. levels at three-year post-transplantation, no statistically significant relationship was observed with the studied genotypes.

\section{Discussion}

Human genome sequencing has shown that genome-wide similarity of three billion base pairs in different individuals is $9.99 \%$. In other words, every person on average is $0.1 \%$ genetically different from other people on Earth. This $0.1 \%$ difference explains why some people are more susceptible to certain diseases and why some are more likely to be healthy than others. It will be beneficial to increase our knowledge of genetic variation in SNPs in parallel with high-throughput technologies of SNP genotyping $(15,16)$.

MicroRNA acts as an important regulator for posttranscriptional modifications. A nucleotide alteration at the target locus sequence can affect microRNA regulation. Many microRNA target sequences are polymorphic, and often these polymorphisms have relatively high abundance in different human populations and affect gene expression, regardless of their effect (benefit, loss, or neutrality). Changes in the ability of the microRNA to bind to the target site as a result of specific polymorphisms can lead to differences in developing genetic diseases (17). For example, according to previous studies, psoriasis (12), spontaneous abortion (18), and intractable Graves' disease (19) have been associated with the FOXP3 rs3761548 AA genotype. In Chinese individuals, the AA genotype has been reported to be associated with allograft rejection (1). In addition, lower graft survival has been reported in Indian individuals with the rs3761548 AA genotype and between the alleles (10).

In the first study to report an association between the genetic variants of the FOXP3 gene and transplant rejection risk in a renal transplant cohort, Qiu et al reported allele 
frequencies of $13.8 \%, 15.9 \%$, and $24.6 \%$ for rs $3761547-\mathrm{G}$, rs3761548-A, and rs2232365-G, respectively, by genotyping results in 166 renal transplant recipients (1). The authors explored whether FOXP3 gene polymorphisms had an impact on renal transplant allograft outcome. The binary logistic regression analysis results indicated that FOXP3 rs3761548 AA genotype carriers were associated with approximately a four-fold increase in risk for allograft rejection compared to those with the CC genotype. This finding suggests that the FOXP3 rs3761548 AA genotype may be a risk factor for incidence of allograft rejection.

Khuja et al studied the FOXP3 rs3761548 C/A gene polymorphism in kidney transplant recipients and the association of this polymorphism with allograft rejection. Of 118 patients, 74 had the CA genotype and 44 had the AA genotype. There was no CC genotype in the population, neither in the 118 patients nor in the 90 control subjects (20). This is in contrast to the study by Qiu et al, in which the CC genotype was the predominant genotype present (1). Khuja et al found that the patients with the CA genotype were more frequent among recipients with fewer rejection episodes. Analysis of the FOXP3 rs3761548 C/A polymorphism revealed that there was a significant rejection rate of $17.6 \%$ in patients with the rs3761548 CA genotype and $40.9 \%$ in patients with the rs3761548 AA genotype (20). This is similar to the results observed by Qiu et al, who found that the risk for allograft rejection in patients with the rs3761548 AA genotype was approximately four-fold greater than in patients with the CC genotype. The rejection rate in patients with CA genotype was $39.1 \%$ (9 of 23 ) compared to $66.7 \%$ (10 of $15)$ in the AA genotype; however, this difference was not significant (1).

Gunesacar et al studied the association of the VEGF $936 \mathrm{C} / \mathrm{T}$ gene polymorphism with graft outcome and found that the $\mathrm{T}$ allele was associated with good graft outcome. The FOXP3 rs3761548 CA polymorphism was also associated with a better response to treatment for rejection and better overall graft function (21). In a study by Schaier et al, FOXP3 regulatory T cells were increased in patients with stable graft function (22). A Korean study also reported that the AA genotype has more likelihood for renal transplant rejection due to a weaker regulatory T cell profile (23). The association between FOXP3 and transplant rejection rate also gives the scope of using regulatory $\mathrm{T}$ cells for preventing allograft rejection.

\section{Conclusion}

There is little evidence regarding the association between these FOXP3 polymorphisms and allograft survival. According to our results, only $10 \%$ of participants experienced episodes of severe kidney dysfunction and we did not find any significant association between kidney function and the subjects' genotypes. Further epidemiologic studies with greater sample sizes may be needed to clarify this association.
Study limitations

The main limitation of the present study is the low sample size, which may affect the findings of this study.

\section{Acknowledgments}

We wish to express our appreciation to the subjects who participated in the study. The results of this article are derived from MD thesis of Solmaz Oloufi (Thesis \#58356).

Authors' contribution

VEA contributed to design of the study, gathering the patients, data entering and data analysis and also preparing the manuscript. MRA cooperated in design of the study and selecting the patients. MJ contributed to preparing the manuscript and final edition. SO participated in gathering the patients. LAM, AAM and DS cooperated in genetic analyses. All authors read and signed the paper manuscript.

Conflicts of interest

The authors declared that there was no conflict of interest.

Ethical considerations

Ethical issues including plagiarism, double publication, and redundancy have been completely observed by the authors.

Funding/Support

This study was supported by a grant from the Research ViceChancellor and kidney Research Center of Tabriz University of Medical Sciences, Tabriz, Iran (Grant \#58356).

\section{References}

1. Qiu XY, Jiao Z, Zhang M, Chen JP, Shi XJ, Zhong MK. Genetic association of FOXP3 gene polymorphisms with allograft rejection in renal transplant patients. Nephrology. 2012;17: 423-430. doi: 10.1111/j.1440-1797.2012.01561.x

2. Fontenot JD, Gavin MA, Rudensky AY. Foxp3 programs the development and function of CD4+ CD25+ regulatory T cells. Nat Immunol. 2003;4: 330-336. doi: 10.1038/ni904

3. Li W, Kuhr C, Zheng X, Carper K, Thomson A, Reyes J, et al. New insights into mechanisms of spontaneous liver transplant tolerance: the role of Foxp3-expressing CD25+ CD4+ regulatory T cells. Am J Transplant. 2008;8:1639-1651. doi: 10.1111/j.1600-6143.2008.02300.x

4. Bennett $\mathrm{CL}$, Ochs HD. IPEX is a unique X-linked syndrome characterized by immune dysfunction, polyendocrinopathy, enteropathy, and a variety of autoimmune phenomena. Curt Opin Pediatr. 2001;13:533-8. doi: 10.1097/00008480200112000-00007

5. Ban Y, Tozaki T, Tobe T, Ban Y, Jacobson EM, Concepcion ES, et al. The regulatory $T$ cell gene FOXP3 and genetic susceptibility to thyroid autoimmunity: an association analysis in Caucasian and Japanese cohorts. J Autoimmun. 2007;28:201-7. doi: 10.1016/j.jaut.2007.02.016

6. Lin Y, Lee J, Wu AS, Tsai C, Yu H, Wang L, et al. Association of single-nucleotide polymorphisms in FOXP3 gene with systemic lupus erythematosus susceptibility: a case-control study. Lupus. 2011;20:137-43. doi: 10.1177/0961203310382428.

7. Sakaguchi S. Naturally arising Foxp3-expressing CD25+ CD4+ regulatory $\mathrm{T}$ cells in immunological tolerance to self and nonself. Nat Immunol. 2005;6:345-52. doi: 10.1038/ni1178

8. Sakaguchi S, Yamaguchi T, Nomura T, Ono M. Regulatory $\mathrm{T}$ cells and immune tolerance. Cell. 2008;133:775-87. doi: 10.1016/j.cell.2008.05.009.

9. Engela AU, Boer K, Roodnat JI, Peeters AM, Eilers PH, Kalvan Gestel JA, et al. Genetic variants of FOXP3 influence 
graft survival in kidney transplant patients. Hum Immunol. 2013;74:751-757. doi: 10.1016/j.humimm.2013.02.008

10. Misra MK, Mishra A, Pandey SK, Kapoor R, Sharma RK, Agrawal $\mathrm{S}$. Association of functional genetic variants of transcription factor Forkhead Box P3 and Nuclear Factor- $\kappa$ B with end-stage renal disease and renal allograft outcome. Gene. 2016;581:5765. doi: 10.1016/j.gene.2016.01.028

11. Bassuny WM, Ihara K, Sasaki Y, Kuromaru R, Kohno H, Matsuura $\mathrm{N}$, et al. A functional polymorphism in the promoter/ enhancer region of the FOXP3/Scurfin gene associated with type 1 diabetes. Immunogenetics. 2003;55:149-56. doi: 10.1007/s00251-003-0559-8

12. Gao L, Li K, Li F, Li H, Liu L, Wang L, et al. Polymorphisms in the FOXP3 gene in Han Chinese psoriasis patients. J Dermatol Sci. 2010;57:51-6. doi: 10.1016/j.jdermsci.2009.09.010

13. Ge J, Wang J, Zhao H, Li K, Jing Y, Li G. Impact of FOXP3 Polymorphisms on the Blood Level of Tacrolimus in Renal Transplant Recipients. Transplant Proc. 2016;481962-7. doi: 10.1016/j.transproceed.2016.04.016.

14. Wu Z, Xu Q, Qiu X, Jiao Z, Zhang M, Zhong M. FOXP3 rs3761548 polymorphism is associated with tacrolimusinduced acute nephrotoxicity in renal transplant patients. Eur J Clin Pharmacol. 2017;73:39-47. doi: 10.1007/s00228-016$2140-z$

15. Sun C, Medvedev P. Toward fast and accurate SNP genotyping from whole genome sequencing data for bedside diagnostics. Bioinformatics. 2019;35:415-420. doi: 10.1093/ bioinformatics/bty 641

16. Shajii A, Yorukoglu D, William Yu Y, Berger B. Fast genotyping of known SNPs through approximate k-mer matching. Bioinformatics. 2016;32:i538-44. doi: 10.1093/bioinformatics/ btw460.

17. Saunders MA, Liang $\mathrm{H}, \mathrm{Li}$ W-H. Human polymorphism at microRNAs and microRNA target sites. Proc Natl Acad Sci U S A. 2007;104:3300-5. doi: 10.1073/pnas.0611347104

18. Wu Z, You Z, Zhang C, Li Z, Su X, Zhang X, et al. Association between functional polymorphisms of Foxp3 gene and the occurrence of unexplained recurrent spontaneous abortion in a Chinese Han population. Clin Dev Immunol. 2011;2012: 896458. doi: 10.1155/2012/896458.

19. Inoue N, Watanabe M, Morita M, Tomizawa R, Akamizu T, Tatsumi K, et al. Association of functional polymorphisms related to the transcriptional level of FOXP3 with prognosis of autoimmune thyroid diseases. Clin Exp Immunol. 2010;162: 402-406. doi: 10.1111/j.1365-2249.2010.04229.x

20. Khuja Z, Parry M, Rasool R, Reshi AR. Association of Forkhead Box P3 gene polymorphisms with allograft rejection episodes in kidney transplant patients. Iran J Kidney Dis. 2018;12:30511.

21. Günesacar R, Opelz G, Erken E, Pelzl S, Döhler B, Ruhenstroth $\mathrm{A}$, et al. VEGF $936 \mathrm{C} / \mathrm{T}$ gene polymorphism in renal transplant recipients: association of the $\mathrm{T}$ allele with good graft outcome. Hum Immunol. 2007;68:599-602. doi: 10.1016/j. humimm.2007.03.015

22. Schaier M, Seissler N, Schmitt E, Meuer S, Hug F, Zeier M, et al. DR high+ CD45RA--Tregs Potentially Affect the Suppressive Activity of the Total Treg Pool in Renal Transplant Patients. PLoS One. 2012;7:e34208. doi: 10.1371/journal.pone.0034208

23. Park H, Lee N, In JW, Roh EY, Park KU, Shin S, et al. Association of Foxp3 polymorphism with allograft outcome in kidney transplantation. Ann Lab Med. 2017;37:420-425. doi: 10.3343/alm.2017.37.5.420 